\title{
Professional Resources
}

\section{Article Explains ISO 9001 Revisions for Manufacturers}

Following the latest update to the revision process for ISO 9001, the global Quality Management System (QMS) standard, Manufacturing.Net has recently published a conversation with LRQA's Senior Technical Manager for North America, Michael Harder, about what ISO issuing ISO/DIS 9001:2014 means for organizations. Questions that are addressed include:

- Now that the ISO/DIS 9001:2014 has been issued, what is the first thing that ISO 9001:2008 certified organizations should be thinking about or doing?

- What are some of the other new topics in ISO/DIS 9001:2014?
- What tools can organizations apply to help them get ready for the transition?

- Who are the most important internal interested parties for organizations in relation to the ISO 9001 revision?

- Will all organizations have to go through the same degree of change to meet the new requirements?

- Could things still change before the final ISO 9001:2015 is issued?

The article is available at www.manufacturing.net/arti cles/2014/06/what-do-iso-9001-revisions-mean-for-manufac turers. 